\title{
Consumo, desempenho e parâmetros econômicos de novilhos Nelore e F1 Brangus x Nelore terminados em pastagens, suplementados com mistura mineral e sal nitrogenado com uréia ou amiréia
}

\author{
[Feed intake, performance and profitability of Nellore and crossbred (Brangus $x$ Nellore) steers finished in pastures, \\ supplemented with mineralized salt and nitrogenous salt with urea or starea] \\ L.C.V.Itavo ${ }^{1,7}$, T.C.P. Tolentino ${ }^{2}$, C.C.B.F. Itavo ${ }^{3}$, R.C. Gomes ${ }^{4}$, A.M. Dias ${ }^{5}$, F.F. Silva ${ }^{6,7}$ \\ ${ }^{1}$ Universidade Católica Dom Bosco \\ Av. Tamandaré, 6000 \\ 79117-900 - Campo Grande, MS. \\ ${ }^{2}$ Zootecnista autônomo \\ ${ }^{3}$ Aluna de pós-graduação - FMVZ-UNESP - Botucatu, SP \\ ${ }^{4}$ Aluno de pós-graduação - FZEA-USP - Pirassununga, SP \\ ${ }^{5}$ Aluno de pós-graduação - UEM - Maringá, PR \\ ${ }^{6}$ Universidade Estadual do Sudoeste da Bahia - Itapetinga, BA \\ ${ }^{7}$ Bolsista do $\mathrm{CNPq}$
}

\begin{abstract}
RESUMO
Avaliou-se o efeito da suplementação protéica $(40 \%$ PB) com amiréia ou uréia sobre o consumo de suplemento, desempenho e características econômicas de novilhos terminados em pastagens. Foram utilizados 120 novilhos com 19 meses de idade e 358kg, sendo 60 Nelore e 60 F1 Brangus x Nelore, divididos em três tratamentos com 20 animais, alojados em piquetes de Brachiaria brizantha cv. Marandu de 10 hectares cada, totalizando 120 hectares, sendo dois piquetes por grupo genético e tratamento, pastejados alternadamente a cada pesagem (42 dias). Os tratamentos consistiram em mistura mineral com amiréia-150S (AM), mistura mineral com uréia+milho+enxofre (UR) e mistura mineral (MM). As médias de consumo de suplemento dos animais F1 foram de 206,1; 145,9 e 73,1g/dia, e as dos animais Nelore, 236,0; 205,1 e 94,3g/dia para os tratamentos AM, UR e MM, respectivamente. Para os novilhos Nelore, houve efeito $(\mathrm{P}<0,05)$ do suplemento sobre o peso de abate $(\mathrm{PA})$, sendo a média do tratamento UR, $518,85 \mathrm{~kg}$, mais alta que a dos demais, 491,89 e $485,20 \mathrm{~kg}$, respectivamente, para AM e MM. Para os novilhos $\mathrm{F} 1$, foi significativo o efeito da suplementação protéica $(\mathrm{P}<0,05)$, com médias de 515,90 e $520,15 \mathrm{~kg}$, respectivamente, para os tratamentos UR e AM. A suplementação protéica proporcionou bom desempenho em animais $\mathrm{F} 1$ durante períodos de abundância de forragem. $\mathrm{O}$ uso de uréia apresentou melhor viabilidade econômica.
\end{abstract}

Palavras-chave: novilho, amiréia, consumo, ganho de peso, suplementação, uréia

\begin{abstract}
The effects of protein supplementation of finishing grazing steers by feeding nitrogenous salts $40 \%$ CP, urea or starea) or mineralized salt only on supplement intake, growing performance and profitability were evaluated. One hundred and twenty steers (60 Nellore and 60 Brangus $x$ Nellore, 19-month old, $358 \mathrm{~kg} \mathrm{BW}$ ) were divided in 12 equal groups which were allotted to one of 12 Brachiaria brizantha pastures (10-ha each) performing two pastures for each breeding group and nutritional treatment. Groups were allowed to graze each pasture for 42 days when they were randomly moved into a new one. Nutritional treatments were as follow: MS - mineralized salt only; ST -mineralized salt plus starea - 150S; and UR - mineralized salt plus urea, corn and sulphur. UR supplement was prepared mixing the same ingredient contents of ST. Crossbred steers consumed 206.1; 145.9 and 73.1g/day whereas Nellore steers consumed 236.0; 205.11 and $94.29 \mathrm{~g} /$ day of ST, UR and MS; respectively. For Nellore steers, UR increased slaughter weight (518.8kg) compared to ST
\end{abstract}


and MS (491.9 and 485.2kg, respectively). Protein supplementation also increased slaughter weight for crossbred steers $(P<0.05)$ in comparison to animals fed mineralized salt as sole supplementation (515.9 and $520.2 \mathrm{~kg}$ for the UR and ST, respectively). Protein supplementation enhances growing performance of crossbred steers during periods of forage abundance. Urea supplementation yields a higher profitability in grazing systems for cattle finishing.

Keywords: steer, intake, starea, supplementation, urea, weight gain

\section{INTRODUÇ̃̃O}

Os ruminantes necessitam de dieta balanceada em energia, proteínas, minerais e vitaminas para promover desempenho satisfatório das funções produtivas. Nas regiões tropicais as pastagens de gramíneas freqüentemente possuem baixos teores de proteína, principalmente durante os períodos críticos do ano. A suplementação protéica pode aumentar a eficiência de utilização de forragens de baixo valor nutricional, principalmente, devido ao atendimento da exigência microbiana ruminal em nitrogênio. Um dos principais componentes do sistema de produção de bovinos é a alimentação e, em especial, as pastagens. Ressalta-se que a competitividade do sistema está diretamente relacionada ao aumento da capacidade de suporte das pastagens (Euclides, 2001). Para qualquer nível de desempenho, a eficiência de ganho é maximizada quando existe equilíbrio entre a exigência e a disponibilidade de nutrientes, pois a interação entre os diferentes nutrientes deve ser monitorada (Paulino et al., 2001).

As pastagens tropicais apresentam períodos de alta produção forrageira, coincidente com a estação das chuvas, e períodos de baixa produção forrageira, durante a estação seca. Algumas práticas de manejo têm sido adotadas para minimizar as perdas ocorridas durante o período de baixa produção forrageira, como a suplementação protéica ou energética (Grandini, 2001; Barbosa et al., 2007).

Níveis elevados de nitrogênio podem induzir à toxidez, pelo excesso de liberação de amônia, com redução do consumo (Silva et al., 2002a); assim, a predição do desempenho animal, mediante suplementação, é um desafio. Uma estratégia de suplementação adequada seria aquela destinada a maximizar o consumo e a digestibilidade da forragem disponível (Kabeya et al., 2002). A uréia é uma das fontes mais utilizadas para suprir parcialmente as deficiências protéicas das pastagens, podendo substituir totalmente os farelos protéicos em dietas para bovinos (Valadares Filho et al., 2002).

Com a finalidade de melhorar a utilização da uréia na alimentação dos animais, foi desenvolvido um produto extrusado à base de amido de milho e uréia, denominado amiréia (Bartley e Deyoe, 1975). Uma das vantagens atribuídas à amiréia é o fato de constituir um complexo de liberação lenta, o que pode reduzir a toxicidade potencial e melhorar a aceitabilidade e a utilização de concentrados à base de uréia.

A pecuária de corte moderna requer animais precoces quanto ao acabamento, adaptados e que apresentem bom ganho de peso. A combinação de raças de origem européia, adaptadas ou não, com raças zebuínas resulta, geralmente, em animais com boa capacidade produtiva em ambientes tropicais (Euclides Filho, 2001).

A utilização de suplementos para bovinos de corte em pasto, há anos, vem sendo pesquisada como alternativa em diferentes situações de produção. Entretanto, sua aplicação é questionável do ponto de vista econômico. Assim, o objetivo foi avaliar o efeito da suplementação com $40 \%$ de proteína bruta (PB) com amiréia e uréia ou suplementação mineral sobre o consumo de suplemento, desempenho produtivo e características econômicas de novilhos Nelore e cruzados (F1 Brangus x Nelore), terminados em pastagens de Brachiaria brizantha cv. Marandu.

\section{MATERIAL E MÉTODOS}

O experimento foi realizado na Fazenda Barroca, situada no município de Ribas do Rio Pardo, MS, entre os meses de maio de 2003 e maio de 2004, totalizando 362 dias. Foram utilizados 120 animais com média de idade de 19 meses e peso médio inicial de $358 \mathrm{~kg}$, sendo 60 animais da raça Nelore e 60 cruzados F1 (Brangus x Nelore). 
Os animais, previamente castrados, foram distribuídos em seis grupos com 20 animais cada, identificados e separados por grupo genético e tratamento. Os tratamentos consistiram em mistura mineral com amiréia (AM), mistura mineral com uréia + milho + enxofre $(U R)$ e mistura mineral (MM). Os seis grupos foram distribuídos em 12 piquetes de Brachiaria brizantha com 10 hectares cada, sendo dois piquetes por grupo (20ha), totalizando 120 hectares, com taxa de lotação inicial de $0,80 \mathrm{UA} /$ hectare.

Foram realizadas amostragens do capim antes da entrada dos animais nos piquetes para determinação da oferta de forragem.
Após as pesagens, realizadas a cada 42 dias, os animais foram encaminhados para piquete diferente daquele anteriormente ocupado, caracterizando um pastejo alternado, em ciclo de pastejo de 84 dias, sendo 42 dias de período de ocupação e 42 dias de período de descanso.

Os suplementos AM, UR e MM foram fornecidos à vontade em cochos cobertos. A cada sete dias foram recolhidas as sobras, que foram pesadas para avaliação do consumo. A proporção dos ingredientes e a composição químicobromatológica dos suplementos fornecidos para novilhos estão demonstradas nas Tab. 1 e 2 .

Tabela 1. Proporção dos ingredientes nos suplementos protéicos fornecidos para novilhos da raça Nelore e F1 Brangus x Nelore

\begin{tabular}{lcc}
\hline Ingrediente & UR & AM \\
\hline Mistura mineral (\%) & 74,40 & 73,66 \\
Uréia (\%) & 14,23 & - \\
Milho moído (\%) & 10,73 & - \\
Enxofre elementar (\%) & 0,64 & - \\
Amiréia 150S (\%) & - & 26,34 \\
\hline
\end{tabular}

$\mathrm{UR}=$ mistura mineral com uréia + milho + enxofre; $\mathrm{AM}=$ mistura mineral com amiréia.

Tabela 2. Composição químico-bromatológica dos suplementos fornecidos para novilhos da raça Nelore e F1 Brangus x Nelore

\begin{tabular}{lcccc} 
Ingrediente & Unidade & UR & AM & MM \\
\hline Matéria seca & $\%$ & 95,95 & 96,82 & 98,00 \\
Proteína bruta & $\%$ & 40,81 & 39,96 & - \\
NNP & $\%$ & 6,40 & 6,25 & - \\
NDT & $\%$ & 8,60 & 9,68 & - \\
Extrato etéreo & $\%$ & 0,39 & 0,43 & 18,50 \\
Cálcio & $\%$ & 13,77 & 13,77 & 6,60 \\
Fósforo & $\%$ & 4,94 & 4,94 & 1,17 \\
Enxofre & $\%$ & 1,51 & 1,51 & 11,84 \\
Sódio & $\%$ & 8,81 & 8,81 & 0,49 \\
Magnésio & $\%$ & 0,38 & 0,38 & 60,00 \\
Cobalto & 44,64 & 44,64 & $1.250,00$ \\
Cobre & $p p m$ & 930,32 & 930,36 & 40,00 \\
Iodo & $p p m$ & 29,76 & 29,77 & 896,00 \\
Ferro & $p p m$ & 669,52 & 669,88 & 996,00 \\
Manganês & $p p m$ & 741,51 & 741,57 & 9,00 \\
Selênio & $\mathrm{ppm}$ & 6,70 & 6,70 & $3.100,00$ \\
Zinco & $\mathrm{ppm}$ & $2.307,75$ & $2.307,92$ & \\
\hline
\end{tabular}

$\mathrm{UR}=$ mistura mineral com uréia + milho + enxofre; $\mathrm{AM}=$ mistura mineral com amiréia;

$\mathrm{MM}=$ mistura mineral; NNP = nitrogênio não protéico; NDT = nutrientes digestíveis totais. 
Entre os meses de julho e outubro (inverno) forneceu-se cana-de-açúcar (Saccharum officinarum L.) em 1\% do PV, em base da MS, a todos os tratamentos, picada, em comedouros distintos dos usados para suplementação protéica ou mineral.

A precipitação pluviométrica $(\mathrm{mm})$ em Campo Grande, MS, durante o período experimental, encontra-se na Fig. 1.

Os dados foram distribuídos em delineamento em blocos ao acaso em esquema fatorial $2 \times 3$ (dois grupos genéticos e três suplementos). As variáveis: consumo, desempenho produtivo, características de carcaça e variáveis econômicas, foram avaliadas por meio de análise de variância, utilizando-se o SAEG (Sistema ..., 1997). Para comparar as médias das variáveis grupo genético e suplemento, utilizou-se o teste Tukey em nível de 5\% de significância. Para comparação das médias de consumo, dentro de tratamento, entre épocas usou-se o teste Wilcoxon, também em nível de 5\% de significância.

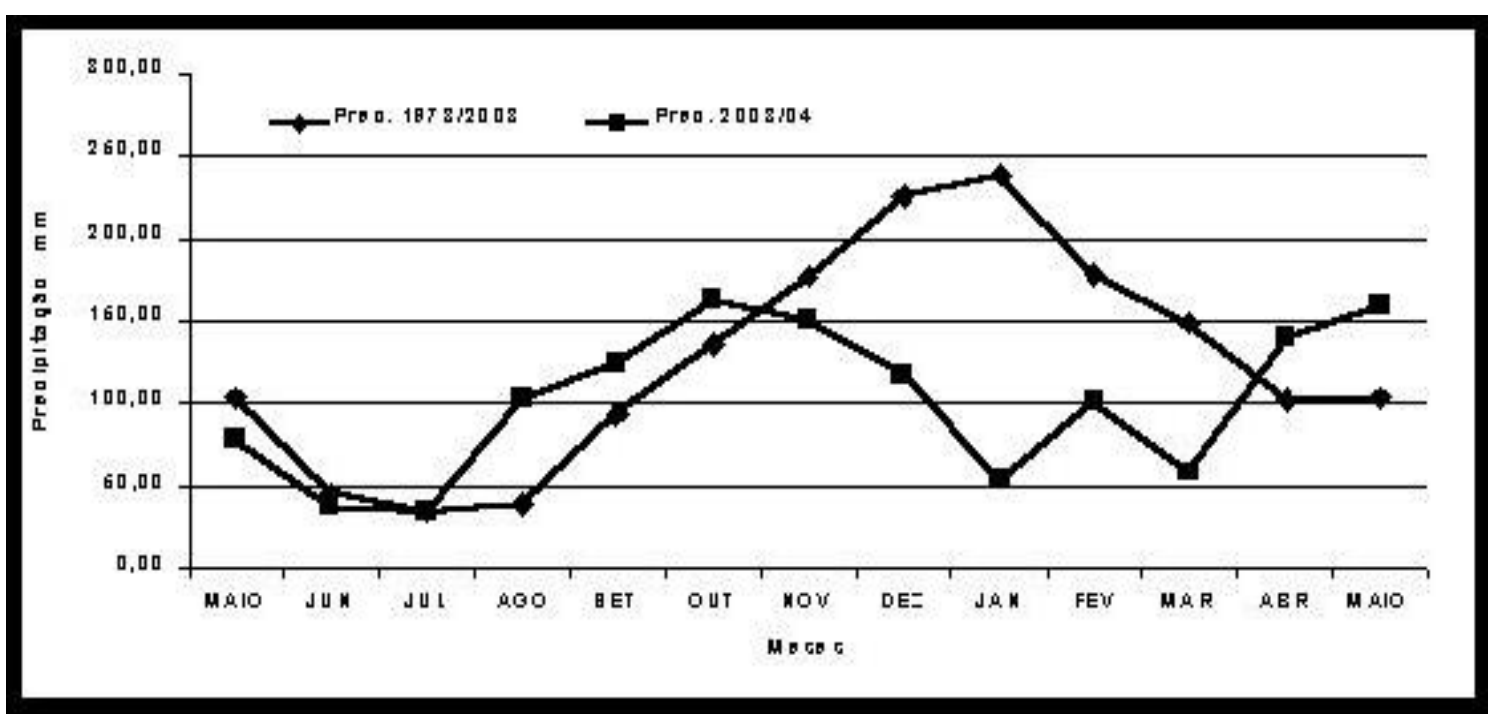

Figura 1. Precipitação pluviométrica (mm) em Campo Grande, MS, no período 2003-2004 e histórico de 31 anos (1973-2003). Fonte: Embrapa Gado de Corte, Campo Grande, MS.

\section{RESULTADOS E DISCUSSÃO}

$\mathrm{Na}$ Tab. 3, são apresentadas as médias de consumo do suplemento, em g/dia, em novilhos F1 Brangus x Nelore e Nelore, em função dos tratamentos, por época do ano e grupo genético. As interações de suplemento e de grupo genético e de época do ano foram significativas $(\mathrm{P}<0,05)$ para consumo de suplemento. Para os animais F1, observou-se maior consumo dos suplementos protéicos (Tab. 3), e menor consumo de UR a partir do inverno $(156,93 \mathrm{~g} / \mathrm{dia})$, com menor valor no outono de 2004 (114,23g/dia), provavelmente devido à melhoria da qualidade da forragem, relacionado aos maiores índices pluviométricos em relação aos demais períodos experimentais (Fig. 1). Este resultado é justificável, pois a forragem proporciona maiores consumos quando da maior permanência em estádio vegetativo, com conseqüente maior aceitabilidade. Ainda, é possível que a baixa utilização da uréia durante o período de inverno por animais em pastejo esteja relacionada ao baixo conteúdo de energia digestível nas forragens. $\mathrm{O}$ menor consumo dos novilhos $\mathrm{F} 1$ ocorreu no tratamento MM, $54,06 \mathrm{~g} / \mathrm{dia}$, no outono de 2004 , e o maior foi no AM, no inverno e no verão, com consumos de 328,03 e $233,79 \mathrm{~g} /$ dia respectivamente, o que pode ter ocorrido devido à melhor aceitabilidade do suplemento (Seixas et al., 1999).

Para novilhos Nelore, os maiores consumos em todos os tratamentos ocorreram principalmente nos períodos de inverno e primavera, sendo que o consumo do tratamento AM no inverno foi de $375,52 \mathrm{~g} / \mathrm{dia}$, mais alto $(\mathrm{P}<0,05)$ que o dos 
tratamentos UR $(254,84 \mathrm{~g} / \mathrm{dia})$ e $\mathrm{MM}$ $(147,93 \mathrm{~g} / \mathrm{dia})$. Nessas condições, a forragem disponível apresenta baixa aceitabilidade ou qualidade, e a procura por suplementos tende a ser mais elevada. Oliveira et al. (2004), ao trabalharem com novilhos Nelore em pastagens de Brachiaria brizantha cv. Marandu, observaram consumo médio de mistura mineral igual a $86 \mathrm{~g} / \mathrm{dia}$ e ganho médio diário igual a $0,27 \mathrm{~g} / \mathrm{dia}$, entre os meses de abril a setembro. Esses resultados são similares aos observados para novilhos Nelore apresentados nas Tab. 3 e Tab. 4.

Tabela 3. Médias de consumo de suplemento, em g/dia, em novilhos F1 Brangus x Nelore e Nelore, em função dos tratamentos, por época do ano e grupo genético

\begin{tabular}{|c|c|c|c|c|c|c|}
\hline \multirow{2}{*}{ Época } & \multicolumn{3}{|c|}{ F1 Brangus x Nelore } & \multicolumn{3}{|c|}{ Nelore } \\
\hline & UR & AM & MM & UR & AM & MM \\
\hline Outono/2003 & $164,48 \mathrm{aA}$ & $104,08 \mathrm{bcC}$ & $76,56 \mathrm{cAB}$ & $164,92 \mathrm{aB}$ & $144,02 \mathrm{abB}$ & $76,35 \mathrm{cB}$ \\
\hline Inverno/2003 & $156,93 \mathrm{bcA}$ & $328,03 \mathrm{aA}$ & $93,99 \mathrm{cA}$ & $254,84 \mathrm{abA}$ & $375,52 \mathrm{aA}$ & $147,93 \mathrm{bAc}$ \\
\hline Primavera/2003 & $145,47 \mathrm{bcAB}$ & $230,21 \mathrm{aAB}$ & $75,17 \mathrm{dAB}$ & $212,76 \mathrm{abAB}$ & $270,57 \mathrm{aAB}$ & $83,22 \mathrm{cdB}$ \\
\hline Verão/2003-04 & $148,54 \mathrm{bcAB}$ & $233,79 \mathrm{aAB}$ & $65,87 \mathrm{~dB}$ & $218,07 \mathrm{aAB}$ & $204,76 \mathrm{abB}$ & $82,61 \mathrm{cdB}$ \\
\hline Outono/2004 & $114,23 \mathrm{cdB}$ & $134,35 \mathrm{bcBC}$ & $54,06 \mathrm{eB}$ & $174,96 \mathrm{abB}$ & $185,12 \mathrm{aB}$ & $81,34 \mathrm{deB}$ \\
\hline
\end{tabular}

$\mathrm{UR}=$ uréia + milho + enxofre + mistura mineral; $\mathrm{MM}=$ mistura mineral; $\mathrm{AM}=$ amiréia + mistura mineral.

Médias seguidas por letras minúsculas distintas na linha diferem entre si pelo teste Tukey $(\mathrm{P}<0,05)$. Médias seguidas das letras maiúsculas distintas na linha, diferem entre si pelo teste Wilcoxon $(\mathrm{P}<0,05)$.

As médias de consumos de suplementos dos animais F1 foram 206,09; 145,93 e 73,13g/dia, e dos animais Nelore, 236,00; 205,11 e 94,29g/dia para os tratamentos AM, UR e MM, respectivamente. Calculando-se a quantidade ingerida de sódio, as médias foram 12,$86 ; 18,16$ e 8,66g/dia para os novilhos F1, e 18,07; 20,79 e 11,16 para os Nelore. Segundo Silva et al. (2002b), a exigência de sódio para novilhos Nelore com $500 \mathrm{~kg}$ é de $4,47 \mathrm{~g} / \mathrm{dia}$, e para animais F1 Europeu-Zebu, 4,72, menores que as recomendações do NRC (Nutrient..., 1996). Todavia as médias de consumo foram mais altas que os valores nacionais tabulados por Silva et al. (2002b). Ítavo e Ítavo (2005), em revisão, citaram que o consumo de misturas minerais por animais em pastejo é altamente variável e afetado pela forragem consumida, estação do ano, suplementos disponíveis, exigências individuais, aceitabilidade da mistura mineral e forma física dos minerais (McDowell, 1996), além da área de cocho e manejo de suplementação.

No verão, observaram-se ganhos de peso (Tab. 4) em todos os tratamentos. Estes resultados confirmam os de Paulino et al. (2001), que verificaram que, durante o período das águas, o objetivo da suplementação seria alcançar ganhos de, aproximadamente, $1,0 \mathrm{~kg} /$ dia. Nesse sentido, Paulino et al. (2002b), ao analisarem o desempenho dos animais sob pastejo na época das águas, observaram ganho médio de $1,16 \mathrm{~kg} / \mathrm{dia}$ em animais suplementados com mistura mineral e consumo de $79 \mathrm{~g} / \mathrm{dia}$.

Tabela 4. Médias de ganho de peso diário (kg/dia), em função dos tratamentos, por época do ano e grupo genético de Novilhos F1 Brangus x Nelore e Nelore

\begin{tabular}{|c|c|c|c|c|c|c|}
\hline \multirow{2}{*}{ Época } & \multicolumn{3}{|c|}{ F1 Brangus x Nelore } & \multicolumn{3}{|c|}{ Nelore } \\
\hline & UR & $\mathrm{AM}$ & MM & UR & $\mathrm{AM}$ & MM \\
\hline Outono/2003 & $0,74 a$ & $0,64 \mathrm{ab}$ & $0,51 \mathrm{ab}$ & $0,69 a$ & $0,62 \mathrm{ab}$ & $0,42 b$ \\
\hline Inverno/2003 & $-0,02 a$ & $-0,02 \mathrm{a}$ & $-0,03$ & $-0,08 \mathrm{a}$ & $-0,10 a$ & $-0,17 a$ \\
\hline Primavera/2003 & $0,18 \mathrm{~b}$ & $0,33 a$ & $0,20 \mathrm{ab}$ & $0,29 \mathrm{ab}$ & $0,31 \mathrm{a}$ & $0,24 \mathrm{ab}$ \\
\hline Verão/2003-04 & $1,04 \mathrm{a}$ & $0,98 \mathrm{a}$ & $0,97 \mathrm{a}$ & $0,64 b$ & $0,72 b$ & $0,72 b$ \\
\hline Outono/2004 & $0,32 \mathrm{c}$ & $0,35 \mathrm{bc}$ & $0,32 \mathrm{c}$ & $0,58 \mathrm{a}$ & $0,38 \mathrm{bc}$ & $0,45 b$ \\
\hline
\end{tabular}

$\mathrm{UR}=$ mistura mineral com uréia + milho + enxofre; $\mathrm{MM}=$ mistura mineral; $\mathrm{AM}=$ mistura mineral com amiréia. Médias seguidas das letras maiúsculas distintas na linha diferem entre si pelo teste Tukey $(\mathrm{P}<0,05)$. 
No inverno, apesar do fornecimento do volumoso suplementar, observou-se perda de peso em todos os tratamentos. A diminuição de oportunidades de pastejo seletivo provoca maior ingestão de forragem madura, com menores teores de nutrientes e digestibilidade, bem como redução do consumo de nutrientes, e apresenta, como conseqüência, redução do ganho (Paulino et al., 2002b). O aporte de nutrientes via suplementação pode visar a níveis diferenciados de desempenho que iniciam na simples mantença de peso e passam por ganhos moderados de cerca de 0,2-0,3kg/dia (Paulino et al., 2001), como ocorrido na primavera de 2003 e no outono de 2004. Na primavera, houve melhora no ganho, comparado ao inverno, pois tanto os novilhos F1 como os Nelores ganharam, em média, $0,22 \mathrm{~kg} /$ dia no tratamento MM. Tal fato está de acordo com Paulino et al. (2001), ao citaram que, na maioria dos casos, é no início da estação chuvosa que se oferecem as melhores oportunidades de ganho de peso.

Zanetti et al. (2000) observaram ganho médio diário (GMD) de $0,36 \mathrm{~kg} /$ dia para animais suplementados com sal proteinado e perda de peso de $0,10 \mathrm{~kg} / \mathrm{dia}$ para animais suplementados apenas com mistura mineral. No entanto, o consumo médio de suplemento protéico foi de $0,65 \mathrm{~kg} / \mathrm{dia}$, superior aos tratamentos UR e AM. Há de se destacar, entretanto, que a qualidade da forragem na primavera (transição seca-águas), associada ao tratamento MM, permitiu que os animais apresentassem ganhos de 0,20 e $0,24 \mathrm{~kg} /$ dia para $\mathrm{F} 1$ e Nelore, respectivamente (Tab. 4), os quais podem ser considerados satisfatórios para animais em pastagens, segundo Euclides (2001) e Paulino et al. (2001).

Oliveira et al. (2004), ao avaliarem o consumo e a digestibilidade de novilhos Nelore em pastagem de Brachiaria brizantha cv. Marandu, e que receberam mistura múltipla contendo uréia ou amiréia, entre os meses de abril e setembro, não observaram efeito da substituição da uréia pela amiréia sobre o desempenho dos animais. Os autores forneceram $800 \mathrm{~g} / \mathrm{dia} / \mathrm{animal}$ de mistura múltipla com $43,3 \%$ e $41,4 \%$ de proteína bruta, sendo que as médias de ganho diário foram 0,43 e $0,42 \mathrm{~g} /$ dia, respectivamente, para os tratamentos com uréia e com amiréia. Esses resultados são mais altos que os ganhos observados neste estudo. Vale ressaltar que o consumo de suplemento (Tab. 3) foi mais baixo que o verificado por Oliveira et al. (2004). Provavelmente, os melhores desempenhos observados pelos autores são devidos ao maior aporte de nutrientes via suplementação, visto que a disponibilidade de forragem foi semelhante (Tab. 5).

$\mathrm{Na}$ Tab. 5, observa-se maior disponibilidade de colmos (ton/ha) do que de folhas (ton/ha) em todas as épocas, com diminuição de ambas no inverno, para os dois grupos genéticos. Houve efeito de época para as variáveis estudadas. Nas épocas de inverno e primavera, houve maior porcentagem de material senescente e, conseqüentemente, menor porcentagem de material vivo. Uma vez que as plantas forrageiras tropicais, devido à elevada taxa de crescimento, perdem o valor nutritivo com o avanço da maturidade, e considerando a preferência dos bovinos pelas rebrotas tenras, o controle sobre o estádio vegetativo da forrageira na época da colheita pelo animal, independentemente da espécie, é o parâmetro que mais afeta a qualidade da dieta, como pode ser observado pelas porcentagens de material senescente nas épocas de inverno e primavera, os quais proporcionaram menor GMD (Tab. 4).

O decréscimo de aproximadamente $50 \%$ da disponibilidade total de forragem verde (tonelada de matéria natural/ha), para ambos os grupos genéticos, do início ao final do experimento, provavelmente, deve-se ao aumento da taxa de lotação. A disponibilidade total de forragem (Tab. 5) possibilitou o pastejo irrestrito e permitiu a seleção, conseqüentemente, possibilitou a maximização do consumo de nutrientes, com provável exceção no inverno de 2003 e no outono de 2004. Portanto, para a obtenção de suprimento abundante de forragem de boa qualidade nessa fase de crescimento intenso das forrageiras, preconiza-se o uso intercalado de manejo para qualidade $\mathrm{e}$ quantidade (Paulino et al., 2001). Assim, visualizam-se ganhos de peso em torno de $1,2 \mathrm{~kg} /$ animal $/$ dia no período de dezembro a fevereiro (Paulino et al., 2002a), como ocorrido no período de verão (Tab. 4 ). 
Tabela 5. Médias de porcentagem de material senescente e vivo (verde), colmos, folhas (\% do material vivo) e disponibilidade total e de folhas em toneladas por hectare, dos piquetes experimentais por época do ano e grupo genético

\begin{tabular}{lccccc}
\hline Suplemento & Outono & Inverno & Primavera & Verão & Outono \\
& 2003 & 2003 & 2003 & $2003-2004$ & 2004 \\
\hline & Novilhos F1 Brangus x Nelore & & & \\
Material senescente (\%) & $24,88 \mathrm{~b}$ & $37,74 \mathrm{a}$ & $37,58 \mathrm{a}$ & $16,96 \mathrm{~b}$ & $20,91 \mathrm{~b}$ \\
Material vivo (\%) & $75,12 \mathrm{a}$ & $62,26 \mathrm{~b}$ & $62,42 \mathrm{~b}$ & $83,04 \mathrm{a}$ & $79,09 \mathrm{a}$ \\
Colmos (\% do vivo) & $57,67 \mathrm{a}$ & $59,56 \mathrm{a}$ & $63,69 \mathrm{a}$ & $63,28 \mathrm{a}$ & $66,46 \mathrm{a}$ \\
Folhas (\% do vivo) & $42,33 \mathrm{a}$ & $40,44 \mathrm{a}$ & $36,31 \mathrm{a}$ & $36,72 \mathrm{a}$ & $33,53 \mathrm{a}$ \\
Disponibilidade de folhas (ton/ha) & $15,53 \mathrm{a}$ & $8,45 \mathrm{c}$ & $11,62 \mathrm{~b}$ & $16,75 \mathrm{a}$ & $6,13 \mathrm{c}$ \\
Disponibilidade de colmos (ton/ha) & $21,17 \mathrm{~b}$ & $12,49 \mathrm{c}$ & $20,46 \mathrm{~b}$ & $27,60 \mathrm{a}$ & $12,17 \mathrm{c}$ \\
Disponibilidade total (ton/ha) & $36,71 \mathrm{ab}$ & $20,95 \mathrm{c}$ & $32,08 \mathrm{~b}$ & $44,35 \mathrm{a}$ & $18,30 \mathrm{c}$ \\
\hline & Novilhos Nelore & & & \\
Material senescente (\%) & $31,25 \mathrm{ab}$ & $37,18 \mathrm{a}$ & $35,53 \mathrm{a}$ & $15,43 \mathrm{c}$ & $19,57 \mathrm{bc}$ \\
Material vivo (\%) & $68,75 \mathrm{bc}$ & $62,82 \mathrm{c}$ & $64,47 \mathrm{c}$ & $84,57 \mathrm{a}$ & $80,43 \mathrm{ab}$ \\
Colmos (\% do vivo) & $55,45 \mathrm{a}$ & $61,61 \mathrm{a}$ & $69,32 \mathrm{a}$ & $65,46 \mathrm{a}$ & $65,73 \mathrm{a}$ \\
Folhas (\% do vivo) & $44,55 \mathrm{a}$ & $38,39 \mathrm{a}$ & $33,68 \mathrm{a}$ & $34,54 \mathrm{a}$ & $34,27 \mathrm{a}$ \\
Disponibilidade de folhas (ton/ha) & $13,80 \mathrm{~b}$ & $9,15 \mathrm{c}$ & $11,07 \mathrm{bc}$ & $17,06 \mathrm{a}$ & $7,17 \mathrm{c}$ \\
Disponibilidade de colmos (ton/ha) & $16,33 \mathrm{bc}$ & $14,60 \mathrm{c}$ & $22,82 \mathrm{ab}$ & $29,84 \mathrm{a}$ & $13,73 \mathrm{c}$ \\
Disponibilidade total (ton/ha) & $30,13 \mathrm{~b}$ & $23,75 \mathrm{c}$ & $33,89 \mathrm{~b}$ & $46,90 \mathrm{a}$ & $20,90 \mathrm{c}$ \\
\hline
\end{tabular}

Médias seguidas por letras minúsculas distintas na mesma linha diferem entre si pelo teste Tukey $(\mathrm{P}<0,05)$.

Na Tab. 6, observa-se que os novilhos F1, em comparação com os Nelore, foram mais pesados $(\mathrm{P}<0,05)$ ao abate (PA), 513,90 e 498,65kg, respectivamente, com diferença de $16,85 \mathrm{~kg}$ para o ganho de peso total (GPT), 156,28 e 139,43kg, respectivamente. Houve efeito da suplementação protéica sobre o desempenho dos novilhos $\mathrm{F} 1$, mas não sobre o dos animais Nelore. Os novilhos F1 que receberam suplementos protéicos apresentaram maior GPT, 156,45 e $163,05 \mathrm{~kg}$, respectivamente, para UR e AM, enquanto o tratamento MM resultou em GPT de 149,35kg.

Tabela 6. Médias de peso de abate (PA), ganho de peso total (GPT), taxa de lotação final (TLF), peso de carcaça quente (PCQ), rendimento de carcaça (RC) e arrobas por hectare (@/ha) em novilhos F1 Brangus $\mathrm{x}$ Nelore e Nelore em função do suplemento

\begin{tabular}{lccccccc}
\hline \multirow{2}{*}{ Variável } & \multicolumn{3}{c}{ F1 Brangus x Nelore } & & \multicolumn{3}{c}{ Nelore } \\
\cline { 2 - 4 } \cline { 6 - 8 } & UR & AM & MM & & UR & AM & MM \\
\hline PA (kg) & $515,90 \mathrm{a}$ & $520,15 \mathrm{a}$ & $505,65 \mathrm{~b}$ & & $518,85 \mathrm{a}$ & $491,89 \mathrm{~b}$ & $485,20 \mathrm{~b}$ \\
GPT (kg) & $156,45 \mathrm{a}$ & $163,05 \mathrm{a}$ & $149,35 \mathrm{~b}$ & & $148,40 \mathrm{~b}$ & $137,44 \mathrm{c}$ & $132,45 \mathrm{c}$ \\
TLF (UA/ha) & $1,15 \mathrm{a}$ & $1,15 \mathrm{a}$ & $1,15 \mathrm{a}$ & & $1,15 \mathrm{a}$ & $1,09 \mathrm{a}$ & $1,08 \mathrm{a}$ \\
PCQ (kg) & $268,85 \mathrm{a}$ & $269,66 \mathrm{a}$ & $259,97 \mathrm{ab}$ & & $275,33 \mathrm{a}$ & $264,81 \mathrm{ab}$ & $254,43 \mathrm{~b}$ \\
RC (\%) & $52,11 \mathrm{a}$ & $51,84 \mathrm{a}$ & $51,41 \mathrm{a}$ & & $53,06 \mathrm{a}$ & $53,83 \mathrm{a}$ & $52,44 \mathrm{a}$ \\
@/ha & $17,92 \mathrm{a}$ & $17,98 \mathrm{a}$ & $17,33 \mathrm{~b}$ & & $18,35 \mathrm{a}$ & $17,65 \mathrm{ab}$ & $16,96 \mathrm{~b}$ \\
\hline
\end{tabular}

UR = mistura mineral com uréia + milho + enxofre; $\mathrm{AM}=$ mistura mineral com amiréia; $\mathrm{MM}$ = mistura mineral; GPT $=$ ganho de peso total; $\mathrm{TL}=$ taxa de lotação; $\mathrm{UA}=450 \mathrm{~kg}$ de peso corporal;

Médias seguidas por letras minúsculas distintas na linha diferem entre si pelo teste Tukey $(\mathrm{P}<0,05)$. 
Os resultados sugerem que a suplementação protéica promoveu melhora das condições ruminais, portanto, não favoreceu $\mathrm{o}$ aproveitamento da forragem, já que o número de animais foi mantido fixo, sendo 20 animais para cada 20 hectares, em pastejo alternado em 10 ha a cada 42 dias, e os resultados de desempenho produtivo dos animais do tratamento $\mathrm{MM}$ foram inferiores para as variáveis PA, GPT, PCQ e arrobas/hectare.

Provavelmente, o melhor desempenho (GPT) dos novilhos $\mathrm{F} 1$ frente à suplementação protéica deve-se ao seu maior potencial genético para ganho de peso em comparação com os animais Nelore. Segundo Paulino et al. (2001), a suplementação de animais em pastejo e a eficiência de ganho podem ter diferentes respostas produtivas, pois dependem de vários fatores e das interações entre eles. Euclides et al. (2001) observaram melhor desempenho de bovinos mantidos em pastagens, suplementados com mistura múltipla em $0,8 \%$ do $\mathrm{PC}$, no entanto, esse melhor desempenho não foi suficiente para compensar os custos adicionais.

Não foi observada diferença no rendimento de carcaça para os diversos tratamentos nos dois grupos genéticos. Kabeya et al. (2002), ao estudarem a suplementação de novilhos mestiços em pastejo na época de transição água-seca, encontraram valor médio de $54,1 \%$ e constataram que o rendimento de carcaça não foi afetado pelos tratamentos.
Os custos com a suplementação, a receita e a margem líquida são apresentados na Tab. 7. Para os animais $\mathrm{F} 1$, o custo com suplementos foi menor em todos os tratamentos em comparação com o dos animais Nelore. A menor despesa com a suplementação dos F1 foi no tratamento MM, e a maior, no AM. O tratamento UR foi economicamente viável, pois $\mathrm{o}$ custo da suplementação dos novilhos F1 foi de R\$ 30,99, com margem líquida de $\mathrm{R} \$ 333,28$, contra $\mathrm{R} \$$ 318,79 e R\$314,99 de margem líquida para AM e $\mathrm{MM}$, respectivamente.

Os animais Nelore do tratamento MM apresentaram menor despesa com suplemento e menor margem líquida, $\mathrm{R} \$ 289,47$ (Tab. 7), devido ao menor peso de abate (Tab. 6). Nos tratamentos UR e AM, as médias de margem líquida foram $\mathrm{R} \$ 345,25$ e $\mathrm{R} \$$ 302,14 , respectivamente, com custo/arroba menor para UR, do que para AM e MM.

Houve diferença na margem líquida por animal $(\mathrm{P}<0,05)$ entre os tratamentos $\mathrm{e}$ os grupos genéticos. Considerando-se a importância por área, essa diferença na margem líquida é de grande importância para o produtor, principalmente nos sistemas de ciclo completo. O tratamento UR apresentou maior $(\mathrm{P}<0,05)$ lucro $(\mathrm{R} \$ /$ arroba $)$. Tal fato deve-se à maior quantidade de arroba produzida por hectare e ao menor consumo de suplemento, comparado ao tratamento AM. O uso de uréia no suplemento apresentou melhor viabilidade econômica, mesmo sendo fornecido durante todo o ano.

Tabela 7. Análise econômica, em função do suplemento por grupo genético de novilhos da raça Nelore e F1 Brangus x Nelore

\begin{tabular}{|c|c|c|c|c|c|c|}
\hline \multirow{2}{*}{ Variável } & \multicolumn{3}{|c|}{ F1 Brangus x Nelore } & \multicolumn{3}{|c|}{ Nelore } \\
\hline & UR & AM & MM & UR & AM & MM \\
\hline Receita (R\$)/animal & $1018,77 \mathrm{~b}$ & $1021,83 b$ & $985,11 \mathrm{c}$ & $1043,31 \mathrm{a}$ & $1012,22 b$ & $964,11 \mathrm{c}$ \\
\hline \multicolumn{7}{|l|}{ Despesas: } \\
\hline Suplemento (R\$/animal) & $30,99 \mathrm{c}$ & $48,54 \mathrm{ab}$ & $15,62 d$ & $43,56 b$ & $55,58 \mathrm{a}$ & $20,14 d$ \\
\hline Animal de reposição & 420,00 & 420,00 & 420,00 & 420,00 & 420,00 & 420,00 \\
\hline Mão-de-obra e medicamentos & 34,50 & 34,50 & 34,50 & 34,50 & 34,50 & 34,50 \\
\hline Custos fixos 1 & 200,00 & 200,00 & 200,00 & 200,00 & 200,00 & 200,00 \\
\hline Margem líquida (R\$/animal) ${ }^{2}$ & $333,28 b$ & $318,79 c$ & $314,99 \mathrm{c}$ & $345,25 a$ & $302,14 c$ & $289,47 d$ \\
\hline Custo (R\$/arroba) ${ }^{3}$ & $38,35 \mathrm{~b}$ & $39,28 \mathrm{a}$ & $38,79 \mathrm{ab}$ & $38,22 b$ & $39,95 \mathrm{a}$ & $39,85 \mathrm{a}$ \\
\hline Lucro (R\$/arroba) ${ }^{4}$ & $19,65 \mathrm{a}$ & $18,72 b$ & $19,21 \mathrm{ab}$ & $19,78 \mathrm{a}$ & $18,05 \mathrm{~b}$ & $18,15 b$ \\
\hline
\end{tabular}

$\mathrm{AM}=$ mistura mineral com amiréia; $\mathrm{UR}=$ mistura mineral com uréia + milho + enxofre; $\mathrm{MM}=$ mistura mineral;

Médias seguidas por letras distintas na linha diferem entre si pelo teste Tukey $(\mathrm{P}<0,05)$, dentro do grupo genético. Preço da @ em maio de 2004=R\$ 58,00 (descontaram-se 2\% de FUNRURAL).

${ }^{1}$ Custos fixos $=$ consideraram-se $2 \%$ de depreciação do valor da terra (R\$ 4.000,00/hectare $* 120$ hectares * 0,02)/120 animais, somado a $\mathrm{R} \$ 10,00$ de aluguel de pasto/animal $/ \mathrm{mês}$.

${ }^{2}$ Margem líquida $=$ receita - Despesas totais.

${ }^{3}$ Custo $(\mathrm{R} \$ /$ arroba $)=$ despesas totais/arrobas totais (peso de carcaça quente/15).

${ }^{4}$ Lucro $(\mathrm{R} \$ /$ arroba $)=$ valor recebido por arroba - custo/arroba. 


\section{CONCLUSÃO}

Recomenda-se suplementação protéica para animais em regime de pastagens para obtenção de melhores desempenhos, desde que haja disponibilidade adequada de pastagem.

\section{REFERÊNCIAS BIBLIOGRÁFICAS}

BARTLEY, E.E.; DEYOE, C.W. Starea as a protein replace for ruminants. Feedstuffs, v.47, p.42-44, 1975.

BARBOSA, F.A.; GRAÇA, D.S.; MAFFEI, W.E. et al. Desempenho e consumo de matéria seca de bovinos sob suplementação protéico-energética, durante a época de transição água-seca. Arq. Bras. Med. Vet. Zootec., v.59, p.160-167, 2007.

EUCLIDES, V.P.B. Produção intensiva de carne bovina em pasto. In: SIMPÓSIO DE PRODUÇÃO DE GADO DE CORTE, 2., 2001, Viçosa. Anais...Viçosa:UFV/DZO, 2001. p.55-82.

EUCLIDES, V.P.B.; EUCLIDES FILHO, K.; COSTA, F.P. et al. Desempenho de novilhos F1s angus-nelore em pastagens de Brachiaria decumbens submetidos a diferentes regimes alimentares. Rev. Bras. Zootec., v.30, p.470-481, 2001.

EUCLIDES FILHO, K. Interação de bovinos de corte e o trinômio genótipo-ambiente-mercado na produção de carne bovina nos trópicos. In: SIMPÓSIO DE PRODUÇÃO DE GADO DE CORTE, 2., 2001, Viçosa. Anais...Viçosa:UFV/DZO, 2001. p.93-115.

GRANDINI, D.V. Produção de bovinos a pasto com suplementos protéicos e/ou energéticos. In: REUNIÃO ANUAL DA SOCIEDADE BRASILEIRA DE ZOOTECNIA, 38., 2001, Piracicaba. Anais... Piracicaba:FEALQ, 2001. p.235-245.

ÍTAVO, L.C.V.; ÍTAVO, C.C.B.F. Formulação de misturas minerais para bovinos de corte. In: CONGRESSO INTERNACIONAL DE ZOOTECNIA, 7., 2005, Campo Grande. Anais... Campo Grande: ZOOTEC:UEMS:ABZ，2005. CDROOM. $17 \mathrm{p}$.

KABEYA, K.S.; PAULINO, M.F.; DETMANN, E. et al. Suplementação de novilhos mestiços em pastejo na época de transição água-seca: desempenho produtivo, características físicas de carcaça, consumo e parâmetros ruminais. Rev. Bras. Zootec.,v.31, p.213$222,2002$.

McDOWELL, L.R., Feeding minerals to cattle on pasture. Anim. Feed Sci. Technol., v.60, p.247-271, 1996.
NUTRIENT requirements of beef cattle. 7.ed. Washington: National Academic of Sciences, 1996. 242p.

OLIVEIRA, L.O.F.; SALIBA, E.O.S.; RODRIGUEZ, N.M. et al. Consumo e digestibilidade de novilhos Nelore sob pastagem suplementados com misturas múltiplas. Arq. Bras. Med. Vet. Zootec., v.56, p.61-68, 2004.

PAULINO, M.F.; DETMANN, E.; ZERVOUDAKIS, J.T. Suplementos múltiplos para recria e engorda de bovinos em pastejo. In: SIMPÓSIO DE PRODUÇÃO DE GADO DE CORTE, 2., 2001, Viçosa. Anais...Viçosa: UFV/DZO, 2001. p.187-231.

PAULINO, M.F.; MORAES, E.H.B.K.; ZERVOUDAKIS, J.T. et al. Suplementação de novilhos mestiços recriados em pastagens de Brachiaria decumbens durante o período das águas: desempenho 1. In: REUNIÃO ANUAL DA SOCIEDADE BRASILEIRA DE ZOOTECNIA, 39., 2002. Recife. Anais... Recife: SBZ, 2002a. (CDROOM)

PAULINO, M.F.; ZERVOUDAKIS, J.T.; MORAES, E.H.B.K. de et al. Bovinocultura de ciclo curto em pastagens. In: SIMPÓSIO DE PRODUÇÃO DE BOVINOS DE CORTE, 3., 2002. Viçosa. Anais... Viçosa: UFV/DZO, 2002b. p.153-196.

SEIXAS, J.R.C.; EZEQUIEL, J.M.B.; ARAÚJO, W.A. et al. Desempenho de bovinos confinados alimentados com dietas à base de farelo de algodão, uréia ou amiréia Rev. Bras. Zootec., v.28, p.432-438, 1999.

SILVA, F.F.; VALADARES FILHO, S.C.V.; ÍTAVO L.C.V. et al. Desempenho produtivo de novilhos Nelore, na recria e na engorda, recebendo dietas com diferentes níveis de concentrado e proteína. Rev. Bras. Zootec., v.31, p.492-502, 2002a.

SILVA, F.F.; VALADARES FILHO, S.C.; ÍTAVO, L.C.V. et al. Exigências líquidas e dietéticas de energia, proteína e macroelementos minerais de bovinos de corte no Brasil. Rev. Bras. Zootec., v.31, p.776-792, 2002b.

SISTEMA de análises estatísticas - SAEG. Viçosa: UFV, 1997.

VALADARES FILHO, S.C.V.; PAULINO, P.V.R.; MAGALHÃES, K.A. et al. Modelos nutricionais alternativos para otimização de renda na produção de bovinos de corte. In: SIMPÓSIO DE PRODUÇÃO DE GADO DE CORTE, 3., 2002, Viçosa. Anais...Viçosa: UFV/DZO, 2002. p.197-254.

ZANETTI, M.A.; RESENDE, J.M.L.; SCHALCH, F. et al. Desempenho de novilhos consumindo suplemento mineral proteinado convencional ou com uréia Rev. Bras. Zootec., v.29, p.935-939, 2000. 